Gary A. Sega, Bruce A. Tomkins, Wayne H. Griest, and Charles K. Bayne

Oak Ridge National Laboratory, Oak Ridge, TN 37831

PECENVED

OCT 271997

Presented to the

OSTI

1997 U. S. Army Edgewood Research, Development, and Engineering Center SCIENTIFIC CONFERENCE ON CHEMICAL AND BIOLOGICAL DEFENSE RESEARCH Edgewood Area Conference Center, Aberdeen Proving Ground, MD November 18-21, 1997
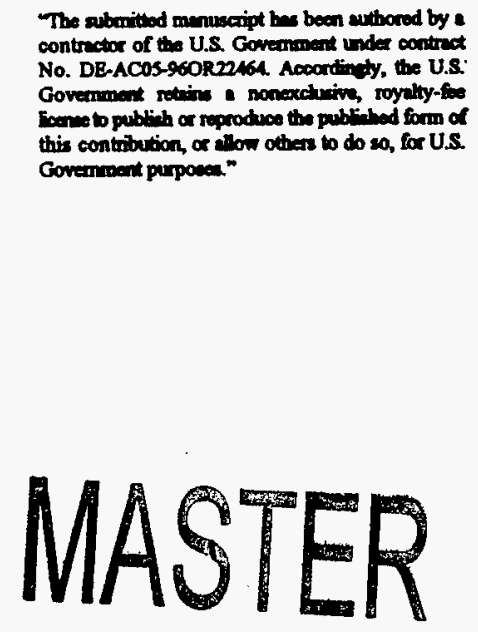


\section{DISCLAIMER}

This report was prepared as an account of work sponsored by an agency of the United States Government. Neither the United States Government nor any agency thereof, nor any of their employees, make any warranty, express or implied, or assumes any legal liability or responsibility for the accuracy, completeness, or usefulness of any information, apparatus, product, or process disclosed, or represents that its use would not infringe privately owned rights. Reference herein to any specific commercial product, process, or service by trade name, trademark, manufacturer, or otherwise does not necessarily constitute or imply its endorsement, recommendation, or favoring by the United States Government or any agency thereof. The views and opinions of authors expressed herein do not necessarily state or reflect those of the United States Government or any agency thereof. 


\title{
THE HYDROLYSIS OF DI-ISOPROPYL METHYLPHOSPHONATE IN GROUND WATER
}

\author{
Gary A. Sega, Bruce A. Tomkins, Wayne H. Griest, and Charles K. Bayne \\ Oak Ridge National Laboratory, Oak Ridge, TN 37831
}

\begin{abstract}
Di-isopropyl methylphosphonate (DIMP) is a byproduct from the manufacture of the nerve agent Sarin. The persistence of DIMP in the ground water is an important question in evaluating the potential environmental impacts of DIMP contamination. The half-life of DIMP in ground water at $10^{\circ} \mathrm{C}$ was estimated to be 500 years with a $95 \%$ confidence interval of 447 to 559 years from measurements of the hydrolysis rates at temperatures between 70 to $98^{\circ} \mathrm{C}$. Extrapolation of the kinetics to $10^{\circ} \mathrm{C}$ used the Arrhenius equation, and calculation of the half-life assumed first-order kinetics. Inorganic phosphate was not detected.
\end{abstract}

\section{INTRODUCTION}

Di-isopropyl methylphosphonate (DIMP) is a by-product from the manufacture of the nerve agent Sarin (isopropyl methylphosphonofluoridate). Leakage of industrial wastes into the water table below unlined waste disposal ponds at a major nerve agent facility during the early $1950 \mathrm{~s}$ led to ground water contamination as great as $44,000 \mu \mathrm{g}$ DIMP/L near abandoned waste disposal ponds ${ }^{1}$ and above $800 \mu \mathrm{g}$ DIMP/L at its North Boundary ${ }^{2}$. Its persistence in the ground water is a key factor in evaluating the potential long-term environmental impacts of DIMP contamination. The only report of a measurement of the hydrolysis rate of DIMP in neutral aqueous media is Bel'skii et al. ${ }^{3}$, in which DIMP was hydrolyzed in neutral water at $80^{\circ}, 90^{\circ}$, and $98^{\circ} \mathrm{C}$. Using the Arrhenius equation and Bel'skii's data, we extrapolated the rate of hydrolysis to $10^{\circ} \mathrm{C}$, the natural temperature of ground water at the site, and predicted a half-life of 948 years with a $95 \%$ confidence interval of 269 to 3,340 years. This half-life needed to be redetermined because a more precise value was required for environmental risk estimates. This paper reports the determination of the hydrolysis rates of DIMP at $70^{\circ}, 81^{\circ}, 90^{\circ}$, and $98^{\circ} \mathrm{C}$ in both ground water and ASTM Type II water, and the estimation of half-lives in these matrices at $10^{\circ} \mathrm{C}$. The concentrations and identities of the resulting primary and secondary hydrolysis products were also studied.

\section{MATERIALS AND METHODS}

\section{Materials}

DIMP (CAS 1445-75-6) was procured from Lancaster Synthesis, Inc. (Windham, NH); its stated purity was $97 \%$. Isopropyl methylphosphonic acid, IMPA [CAS No. 1832-54-8] was obtained from the U.S. Army Toxic and Hazardous Materials Agency (now the Army Environmental Center) Standard Analytical Reference Materials Repository (Research Triangle Park, NC). Methylphosphonic acid (MPA), CAS No. 993-13-5, and trimethylphosphate (TMP), CAS 512-56-1, were purchased from the Aldrich Chemical Co. (Milwaukee, WI). HPLC-grade water (used as ASTM Type II water) and methanol were obtained from J. T. Baker (Phillipsburg, NJ). Trimethylphenylammonium hydroxide (TMPAH) $(0.1 \mathrm{M}$ 
in methanol) was purchased from the Eastman Kodak Co. (Rochester, NY) and from Fluka Chemicals, (Ronkonkoma, $\mathrm{NY}$ ), and concentrated to $0.3 \mathrm{M}$ before use.

\section{Sorbents}

BAKERBOND Quaternary 'Amine $\left(\mathrm{N}^{+}\right) 3 \mathrm{~mL}, 500 \mathrm{mg}$ SPE columns, were obtained from J.T. Baker. SPEC.3ML-C18AR solid phase extraction disks (15 mg sorbent per disk) mounted in $3 \mathrm{~mL}$ columns were obtained from SPEC • division of ANSYS, Inc. (Irvine, CA).

\section{Preparation of Standard Ground Water Surrogate}

The standard ground water surrogate matrix ${ }^{4}$ was made by dissolving $165 \mathrm{mg}$ of sodium chloride and $148 \mathrm{mg}$ of sodium sulfate in $1 \mathrm{~L}$ of HPLC-grade water. Final chloride and sulfate concentrations were each $100 \mathrm{mg} / \mathrm{L}$. ASTM Type II water alone was used for the blanks matched to samples of ASTM Type II water spiked with DIMP.

\section{Outline of Hydrolysis Experiments}

DLMP Hydrolysis. Eight 1-L samples of ground water received from the Intercept and Treatment System north of Rocky Mountain Arsenal (Commerce City, $\mathrm{CO}$ ) were pooled and mixed thoroughly, then returned to their original 1-L containers. The "native" concentration in the homogeneous ground water was estimated to be $500 \mu \mathrm{g}$ DIMP/L (ppb) using an

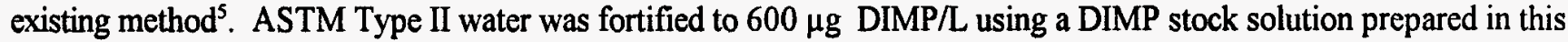
laboratory. Aliquots $(21 \mathrm{~mL})$ of each type of water sample were pipetted into glass ampules. These were flame-sealed, and placed together in ovens maintained at $70,81,90$, and $98 \pm 11^{\circ} \mathrm{C}$. Four ampules each of the authentic ground water and ASTM Type II water were removed from the ovens at varying times and analyzed for DIMP as described in detail below.

Formation of DMP By-Products. Authentic ground water was fortified with DIMP to a final concentration of $2440 \mu \mathrm{g} / \mathrm{L}$. Aliquots were sealed in glass ampules and heated to $90^{\circ} \mathrm{C}$. Four ampules were analyzed at various intervals.

IMPA Hydrolysis. Ground water surrogate was fortified to $10,000 \mu \mathrm{g}$ IMPA/L, sealed in glass ampules, and heated to $90^{\circ} \mathrm{C}$. Ampules were analyzed for IMPA and MPA over a 71-day period using a solid phase extraction method, as described below.

\section{Solid Phase Extraction (SPE) Procedures}

DIMP Hydrolysis. The extraction of DIMP was performed using SPEC $3 \mathrm{ML} \cdot \mathrm{C} 18 \mathrm{AR}$ solid phase extraction disks mounted in 3-mL capacity columns, which were attached to a twelve-port vacuum manifold (Alltech Associates, Deerfield, IL). The disks were conditioned with methanol and water before extracting $20 \mathrm{~mL}$ sample. After the disks were dried using partial vacuum, DIMP was eluted was eluted using a single $1.1 \mathrm{~mL}$ portion of methanol (approximately $1 \mathrm{~mL}$ is recovered).

Formation of DIMP By-Products. The extraction of DIMP, IMPA and MPA was performed using anion exchange SPE media similar to the method of Tomes and Johnsen ${ }^{6}$, as modified in our laboratory ${ }^{7}$. The SPEC.3ML $\cdot \mathrm{Cl} 18 \mathrm{AR}$ extraction columns were conditioned as described previously, then "stacked" onto quaternary amine (500 mg sorbent) columns which had been conditioned with methanol and water. Aqueous sample was passed through both extraction columns, which were 
separated and attached to the vacuum manifold. The quaternary amine columns only were rinsed with an additional 1 $\mathrm{mL}$ methanol. Columns were dried using partial vacuum for approximately $0.5-1 \mathrm{hr}$. After drying, the vacuum was released and a rack holding collection vessels was placed in the manifold housing. The SPEC $\cdot 3 \mathrm{ML} \cdot \mathrm{C} 18 \mathrm{AR}$ columns were eluted as described above. The phosphonic acids were eluted from the quaternary amine columns using a single 1.4 $\mathrm{mL}$ aliquot of $0.3 \mathrm{M} \mathrm{TMPAH}$ (approximately $1 \mathrm{~mL}$ recovered), which was collected directly into $2 \mathrm{~mL}$ autosampler vials. Exact volumes recovered for each sample were determined by weighing the extract and multiplying by the reagent density $\left(0.885 \mathrm{~g} / \mathrm{mL}\right.$ at $\left.25^{\circ} \mathrm{C}\right)$.

In the experiment to study the hydrolysis of IMPA, only the quaternary amine columns were used.

\section{Gas Chromatography of DIMP. IMPA, and MPA}

A Varian (Sunnyvale, CA) model 3400 capillary column gas chromatograph (GC) equipped with a flame photometric detector (FPD) in its phosphorus-selective mode and a septum-programmable injector (SPI) was used for all measurements. A Varian $8200 \mathrm{CX}$ autosampler was used for automated injections. The deactivated glass inlet SPI sleeve featured deactivated fused silica wool, fused silica beads, and additional deactivated fused silica wool (Restek, Bellefonte, PA). A capillary Rtx 8 -5 (crossbond 5\% diphenyl - 95\% dimethylpolysiloxane) fused-silica column, $30 \mathrm{~m}, 0.53 \mathrm{~mm}$ I.D., $1.5 \mu \mathrm{m}$ film (Restek) was used for the chromatographic separations. The column oven temperature increased linearly from $70^{\circ} \mathrm{C}$ to $100^{\circ} \mathrm{C}$ (hold for $6 \mathrm{~min}$ ) at $5^{\circ} \mathrm{C} / \mathrm{min}$. The injector and detector temperatures were $350^{\circ} \mathrm{C}$ and $200^{\circ} \mathrm{C}$, respectively. The carrier gas (helium), make-up gas (nitrogen), hydrogen, and air flows were set to factory-recommended values. Samples $(1 \mu \mathrm{L})$ were injected after a needle dwell time of $4 \mathrm{sec}$ in the injection port. The analyte concentrations were determined using the method of external standards.

\section{Quantitation of DIMP, IMPA, and MPA}

DIMP concentrations were calculated from GC peak areas using a calibration curve generated from spiked DIMP concentrations in methanol. The linear range of the calibration curve was 0 to $20,000 \mu \mathrm{g}$ DIMP/L. The calculated DIMP concentrations were adjusted for overall method recovery, which was estimated from a linear fit of measured vs spiked DIMP concentrations in ASTM Type II. The ASTM Type II water was assumed to have a matrix effect identical to that of authentic ground water. The overall method recovery with $95 \%$ confidence interval was estimated to be $92.2 \pm 4.8 \%$.

\section{Measurement of Inorganic Phosphate}

Inorganic phosphate was determined using U.S. Environmental Protection Agency Method 300.0 $0^{8}$, which describes the ion chromatographic determination of orthophosphate and other inorganic contaminants of environmental samples.

\section{RESULTS AND DISCUSSION}

\section{Estimation of DIMP Half-life}

The estimation of the half-life of DIMP in ground water at its natural temperature of approximately $10^{\circ} \mathrm{C}$ was approached by first measuring the hydrolysis rate constants (first-order kinetics assumed) at four elevated temperatures. The rate constants for DIMP hydrolysis in the two samples matrices and at the four temperatures are listed in Table I, 
which also includes the rate constants, $\mathbf{k}$, calculated by Bel'skii et $\mathbf{a l}^{3}{ }^{3}$ and Hudson and Keay'.

TABLE 1

Rate Constants for DIMP Hydrolysis

\begin{tabular}{|c|c|c|c|c|c|}
\hline $\mathrm{t},{ }^{\circ} \mathrm{C}$ & $k, D^{-1}$ & $\begin{array}{c}\text { Standard } \\
\text { Deviation, } D^{-1}\end{array}$ & $\begin{array}{c}95 \% \text { Confidence } \\
\text { Interval, } \mathrm{D}^{-1}\end{array}$ & $\begin{array}{l}\text { Sample } \\
\text { Matrix }\end{array}$ & Reference \\
\hline 70 & 0.01237 & 0.00047 & \pm 0.00098 & \multirow{4}{*}{$\begin{array}{l}\text { Ground } \\
\text { Water }\end{array}$} & \multirow{4}{*}{ This study } \\
\hline 81 & 0.04091 & 0.00145 & \pm 0.00300 & & \\
\hline 90 & 0.10180 & 0.00121 & \pm 0.00251 & & \\
\hline 98 & 0.22069 & 0.00303 & \pm 0.00636 & & \\
\hline 70 & 0.01174 & 0.00035 & \pm 0.00073 & \multirow{4}{*}{$\begin{array}{l}\text { ASTM } \\
\text { Type II } \\
\text { Water }\end{array}$} & \multirow{4}{*}{ This study } \\
\hline 81 & 0.04103 & 0.00204 & \pm 0.00422 & & \\
\hline 90 & 0.10567 & 0.00094 & \pm 0.00195 & & \\
\hline 98 & 0.22964 & 0.00451 & \pm 0.00947 & & \\
\hline 80 & 0.02678 & Not reported & Not reported & \multirow{3}{*}{$\begin{array}{c}\text { Neutral } \\
\text { Water }\end{array}$} & \multirow{3}{*}{ Bel'skii et al. } \\
\hline 90 & 0.07603 & Not reported & Not reported & & \\
\hline 98 & 0.1728 & Not reported & Not reported & & \\
\hline $\begin{array}{l}88.9 \\
99.7\end{array}$ & $\begin{array}{l}15.0 \\
41.3\end{array}$ & $\begin{array}{l}\text { Not reported } \\
\text { Not reported }\end{array}$ & $\begin{array}{l}\text { Not reported } \\
\text { Not reported }\end{array}$ & $\begin{array}{c}\text { Water } \\
\text { Acidified w/ } \\
\text { HCL, pH } \sim 0\end{array}$ & Hudson and Keay \\
\hline 80 & $13.2^{1}$ & Not reported & Not reported & \multirow{3}{*}{$\begin{array}{c}\text { Water Made } \\
\text { Alkaline w/ } \\
\mathrm{NaOH}, \\
\mathrm{pH} \sim 13.3\end{array}$} & \multirow{3}{*}{ Hudson and Keay } \\
\hline 90 & 19.8 & Not reported & Not reported & & \\
\hline 100 & 41.6 & Not reported & Not reported & & \\
\hline
\end{tabular}

${ }^{1}$ Second-order rate constant with units L-moles ${ }^{-1}-\mathrm{D}^{-1}$

The rate constants were assumed to obey the Arrhenius equation, $k=A \exp (-E / R T)$, where $A$ is the preexponential factor (also called the frequency factor), $E$ is the activation energy in cal mole ${ }^{-1}, R$ is the gas law constant of $1.9872 \mathrm{cal}^{\circ} \mathrm{K}^{-1} \mathrm{~mole}^{-1}$, and $\mathrm{T}$ is the temperature in ${ }^{\circ} \mathrm{K}$. This equation was rearranged after taking the natural logarithm of each side to yield

$\ln k=\ln A-(E / R) *(1 / T)$ 
The $(1 / T)$ values were plotted versus $\ln k$ and fitted to a straight line using a least-squares regression analysis. The slope of the plot represents $-E / R$, the activation energy divided by the gas law constant, and the intercept is $\ln A$. The parameters $A$ and $E$ are listed in Table 2 and compared with values taken from or calculated using data in the literature.

TABLE 2

Activation Energies and Pre-exponential Factor for DIMP Hydrolysis

\begin{tabular}{|c|c|c|c|c|c|}
\hline $\begin{array}{l}\text { Sample } \\
\text { Matrix }\end{array}$ & $\begin{array}{c}\mathrm{E}, \\
\mathrm{Cal} / \mathrm{mole}\end{array}$ & $\begin{array}{l}\text { Std. Dev. of E, } \\
\text { Cal/mole }\end{array}$ & $A, D^{-1}$ & Std. Dev. of A & Reference \\
\hline $\begin{array}{l}\text { Ground } \\
\text { Water }\end{array}$ & 26,000 & 68 & $4.76 \mathrm{E}+14$ & $4.6 \mathrm{E}+13$ & This Study \\
\hline $\begin{array}{c}\text { ASTM } \\
\text { Type } \\
\text { II Water }\end{array}$ & 26,900 & 230 & $1.63 E+15$ & $5.2 \mathrm{E}+14$ & This study \\
\hline "Water" & 26,900 & Not reported & $1.48 \mathrm{E}+10$ & Not reported & Bel'skii et al. \\
\hline $\begin{array}{l}\text { Acid }^{1}, \\
\mathrm{pH} \sim 0\end{array}$ & 25,600 & Not calculated & $1.72 \mathrm{E}+17$ & Not calculated & Hudson and Keay \\
\hline $\begin{array}{l}\text { Alkaline }^{1} \\
\mathrm{pH} \sim 13.3\end{array}$ & 14,900 & Not reported & $6.9 \mathrm{E}+9^{2}$ & Not calculated & Hudson and Keay \\
\hline
\end{tabular}

${ }^{1}$ The results were calculated from the data reported in Hudson and Keay, Reference 9.

${ }^{2}$ Units for $A$ in second-order reaction are L-mole ${ }^{-1}$-day ${ }^{-1}$

The rate constant $\mathrm{k}_{10}$ for $10^{\circ} \mathrm{C}$, the natural temperature of the ground water, was predicted from the Arrhenius least-squares analysis along with a $95 \%$ confidence interval on the predicted value ${ }^{10}$. A predicted half-life, $\tau_{1 / 2}$, of DIMP was calculated using the following equation:

$$
\tau_{1 / 2}=\frac{\ln 2}{365 * k_{10}}
$$

The half-lives of DIMP in ground water and in ASTM Type II water are presented in Table 3 along with a similar prediction calculated using the data of Bel'skii et al. The calculated half-life of DIMP in ground water is approximately 500 years, and this value was not substantially different from either that measured in ASTM Type II water, or from the prediction made using Bel'skii's data. The latter is true mainly because of the lesser precision of the data reported in Bel'skii's study. Thus, we confirmed the very long half-life of DIMP in ground water, and improved upon the precision of the prediction based upon the previous study. 
TABLE 3.

Estimated Rate Constant and Half-life Data for DIMP at $10^{\circ} \mathrm{C}$ with $95 \%$ Confidence Intervals

\begin{tabular}{ccccc}
\hline Sample Matrix & $\mathrm{k}_{10}, \mathrm{D}^{-1}$ & $\tau_{1 / 2}$, years & $95 \%$ CI for $\tau_{1 / 2}$,years & Reference \\
\hline $\begin{array}{c}\text { Ground water } \\
\text { ASTM Type II } \\
\text { water }\end{array}$ & $3.81 \mathrm{E}-6$ & 500 & $447-559$ & This study \\
"Water" & $2.78 \mathrm{E}-6$ & 684 & $470-995$ & This study \\
Acid, pH $\sim 0$ & $2.00 \mathrm{E}-6$ & 948 & $269-3340$. & Bel'skii et al. \\
$\begin{array}{c}\text { Alkaline, } \mathrm{pH} \sim \\
13.3\end{array}$ & $3.67 \mathrm{E}-2$ & 0.75 & Not calculated & Hudson and Keay \\
\hline
\end{tabular}

\section{DIMP Hydrolysis Products}

Isopropyl methylphosphonic acid (IMPA) is expected to be the primary product of DIMP hydrolysis ${ }^{9}$. The literature of chemical warfare agent hydrolysis indicates that secondary products such as methylphosphonic acid (MPA) and possibly inorganic phosphate should be observed ${ }^{6,11,12}$. Keay (reference 12) found that the rate of IMPA hydrolysis was very slow compared that of Sarin.

Using the hydrolysis rate data reported in reference 12, we estimate the half-life of IMPA to be about 1920 years at $10^{\circ} \mathrm{C}$ and 87 years at $25^{\circ} \mathrm{C}$, both in $1 \mathrm{~N}$ benzenesulfonic acid. The rate would be even slower in neutral solutions such as ground water. This very slow rate of IMPA hydrolysis may explain why some groups have failed to detect MPA.

The ultimate hydrolysis product of DIMP should be inorganic phosphate. Schowanek and Verstraete ${ }^{13}$ found that MPA is hydrolyzed to this moiety in aqueous solution in the presence of divalent cations such as $\mathrm{Ca}$ (II), $\mathrm{Mg}(\mathrm{II})$, and $\mathrm{Fe}$ (II). The half-life of MPA at a pH of 7.0 and $28^{\circ} \mathrm{C}$ ranged from about 14 to 24 years, depending on the hydrolysis media. Thus, it appears that after DIMP is hydrolyzed, the IMPA formed is degraded more slowly than MPA, so that IMPA should accumulate. To test this hypothesis, a sample of ground water was fortified with DIMP to a final concentration of $2440 \mu \mathrm{g} / \mathrm{L}$, and aliquots were heated to $90^{\circ} \mathrm{C}$. At intervals, four ampules were withdrawn from the oven. DIMP, IMPA, and MPA were extracted using SPE with stacked C-18 sorbent disks and quaternary amine SPE columns. Separation and quantitation were performed using GC-FPD. As DIMP disappeared, IMPA and MPA appeared. The IMPA concentration increased with time, but the MPA concentration was variable and did not increase steadily. The total concentration of the DIMP and its products did not account for all of the DIMP that disappeared. At the end of the experiment (42.8 days), the molar accounting of unreacted DIMP and detected products was about $15 \%$. This consisted of $4 \%$ nonhydrolyzed DIMP, $9 \%$ IMPA, and $2 \%$ MPA.

The hydrolysis rate of IMPA was examined under conditions similar to those in the previous experiment. Model ground water (ASTM Type II water fortified with sulfate and chloride, reference 4) was fortified to $10,000 \mu \mathrm{g} \mathrm{IMPA} / \mathrm{L}$, and ampules were maintained at $90^{\circ} \mathrm{C}$. This matrix contains no inorganic phosphate which might suppress the IMPA hydrolysis and shift the reaction back towards starting material. Ampules were removed over a 71-day period and wcre analyzed for IMPA and MPA. The half-life of IMPA in the model ground water was calculated to be approximatcly 777 
days. By contrast, the estimated half-life for DIMP in ASTM Type II water at $90^{\circ} \mathrm{C}$ was 6.6 days, or approximately 120 times faster than that for IMPA. Only a small constant concentration of MPA was observed in this experiment.

In the DIMP hydrolysis experiment, a small peak was observed at the retention time of trimethyl phosphate (TMP) in the GC-FPD chromatogram. This peak could correspond to inorganic phosphate. To determine if inorganic phosphate could represent the unaccounted DIMP hydrolysis product, a sample of ASTM Type II water was fortified to $10,000 \mu \mathrm{g}$ DIMP/L, and aliquots were subsequently sealed in ampules. One of these was stored at $98^{\circ} \mathrm{C}$, while the control was maintained at room temperature. After one week, the contents of both ampules were analyzed using ion chromatography, and inorganic phosphate was not detected above the detection limit of $500 \mu \mathrm{g} / \mathrm{L}$. This result suggests that the GC-FPD peak observed at the retention time of TMP in the hydrolysis of DIMP did not correspond to inorganic phosphate. At the present time, we do not have an explanation for either the apparent lack of inorganic phosphate or the clear disparity in the molar accounting for DIMP and its hydrolysis products.

\section{CONCLUSIONS}

The results of this study confirm that the hydrolysis of DIMP proceeds very slowly in neutral aqueous solutions at $10^{\circ} \mathrm{C}$. DIMP should be very persistent in ground water, with a calculated half-life of approximately 500 years. Although hydrolyses performed at elevated temperatures demonstrated that IMPA was the major product observed, the very slow rate of DIMP hydrolysis in ground water suggests that the unidentified products are not likely to accumulate to any significant extent.

\section{ACKNOWLEDGMENTS}

Research sponsored by the Rocky Mountain Arsenal, DOE No. 1989-H077-A1, U.S. Department of Energy under contract DE-AC05-96OR22464 with Oak Ridge National Laboratory, managed by Lockheed Martin Energy Research Corp.

\section{REFERENCES}

1. Robson, S.G. "ASTM Spec. Tech. Publ. 746 (Permeability Ground Water Contamination Transport)," 209-220 (1981).

2. Zappi, M.E., Fleming, E.C., Thompson, D.W. and Francingues, Jr., N. R., "Proceedings of the Seventh National Conference on Hazardous Wastes and Hazardous Materials," $405-409$ (1990).

3. Bel'skii, V.E., Motygullin, G.Z. and Grishina, O.N., Izvestiya Akademii Nauk SSSR, Seriya Khimicheskaya, 12, 2813-2814 (1969).

4. "Program Manager for Rocky Mountain Arsenal: Chemical Quality Assurance Plan, Version I," U. S. Army Materiel Command, Program Manager Rocky Mountain Arsenal, Commerce, CO (September, 1993). 


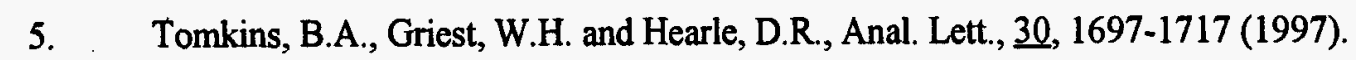

6. Tornes, J.A. and Johnsen, B.A., J. Chromatogr., 467, 129-138 (1989).

7. Sega, G.A., Tomkins, B.A. and Griest, W.H., J. Chromatogr. A (in press) (1997).

8. Pfaff, J.D. "Method 300.0, Determination of Inorganic Anions by Ion Chromatography, Revision 2.1." U. S. Environmental Protection Agency, Environmental Monitoring Systems Laboratory, Office of Research and Development, Cincinnati, OH (August 1993).

9. Hudson, R.F. and Keay, L., J. Chem. Soc., 2463-2469 (1956).

10. Draper, N.R and Smith, H., "Applied Regression Analysis, Second Edition," John Wiley \& Sons, Inc., New York (1981).

11. Kingery, A.F. and Allen, H.E., Toxicol. and Environ. Chem., 47, 55-184 (1995).

12. Keay, L., Can. J. Chem., 43, 2637-2639 (1965).

13. Schowanek, D. and Verstraete, W., J. Environ. Quality, 20, 769-776 (1991). 


$$
\text { Doe }
$$

19971202082 